\title{
Análisis argumentativo de la sentencia del Tribunal Constitucional en el caso PUCP
}

\author{
FÉLIX MORALES LUNA*
}

\section{INTRODUCCIÓN}

Analizar una argumentación jurídica implica atender a las razones que fundamentan una determinada decisión en el Derecho, lo cual nos permite detectar sus puntos fuertes y débiles, así como calificarla como una decisión correcta o incorrecta, según se base en razones suficientes y adecuadas o no lo haga.

El propósito de este trabajo es analizar la argumentación jurídica contenida en la sentencia recaída en el Expediente 03347-2009-PA/TC expedida por el Tribunal Constitucional del Perú el pasado 17 de marzo de 2010, y suscrita por cuatro magistrados, a propósito del recurso de agravio constitucional presentado por la Pontificia Universidad Católica del Perú contra la sentencia de la Octava Sala Civil de la Corte Superior de Justicia de Lima en la controversia que mantiene contra el señor Walter Muñoz Cho.

\section{II.LA ARGUMENTACIÓN JURÍDICA DEL VOTO EN MAYORÍA DEL TRIBUNAL CONSTITUCIONAL}

A partir de la lectura de la sentencia, es posible reconstruir del siguiente modo la argumentación jurídica de los cuatro magistrados que suscriben la sentencia en mayoría ${ }^{1}$ :

1. Un primer problema que se plantean los magistrados es el siguiente: ise debe declarar la nulidad de la sentencia de la Octava Sala Civil de la Corte Superior de Lima? Esta pregunta es respondida negativamente por considerar que «no existe vicio que acaree la nulidad de la sentencia, pues [...] aparece suscrita por los señores magistrados que emitieron sus respectivas ponencias, no afectándose en modo alguno el sentido del fallo» (punto 6 del fundamento $§ 1$ ).

* Doctor en Derecho por la Universidad de Alicante y profesor de la Facultad de Derecho de la Pontificia Universidad Católica del Perú.

1 La reconstrucción de una argumentación jurídica realizada por un tribunal no resulta ser una labor puramente descriptiva, pues en muchos momentos quien analiza debe tomar ciertas decisiones para interpretar el sentido del texto analizado (Atienza, Manuel. «Análisis de las argumentaciones jurídicas». En Manuel Atienza y Alí Lozada. ¿Cómo analizar una argumentación jurídica? Quito: Cevallos, 2009, p. 21). No obstante, en atención al denominado principio de caridad, he intentado presentar los argumentos de la sentencia en mayoría del Tribunal Constitucional de la forma más ordenada posible, a pesar de la confusión y del desorden en que son presentados los argumentos y aun cuando en ciertos pasajes la sentencia presenta una redacción oscura y en otros presenta argumentos que, por su sentido y énfasis, parecen alegatos de una parte más que razones de un tribunal imparcial. 
2. Un segundo problema está determinado por la competencia que tendría el Tribunal Constitucional para resolver esta controversia. Así, la pregunta sería ies competente el Tribunal Constitucional para conocer esta controversia? Esta pregunta es respondida afirmativamente por considerar que la herencia es una materia constitucionalmente relevante (punto 19 del fundamento $\$ 3$ ).

3. Un tercer problema consiste en la siguiente pregunta: ilos actos del demandado amenazan los derechos constitucionales de la universidad? Para determinar si se ha configurado la amenaza o no a los derechos de la PUCP, el Tribunal Constitucional se plantea los siguientes subproblemas:

3.1. ¿Qué testamento debe prevalecer: el de 1933 o el de 1938? Esta pregunta, planteada como «cuestión central» en la sentencia (punto I del fundamento 20), tiene como respuesta que debe prevalecer el testamento de 1938. Esta conclusión se basa, principalmente, en la doctrina, la jurisprudencia y la legislación vigentes (punto VII.c del fundamento 20), así como en la analogía entre los testamentos y las leyes, pues la ley posterior elimina a la anterior (punto IX.1. del fundamento 20).

3.2. ¿La Junta de Administración debe participar en la administración de los bienes de la PUCP tras haberse cumplido los veinte años del fallecimiento del testador? Los magistrados responden a esta pregunta afirmativamente, pues consideran, principalmente, la literalidad del testamento de 1938 (punto IX.3. del fundamento 20).

3.3. iEs válido el acuerdo de 1994 de la Junta de Administración? Este problema, a su vez, plantea los siguiente subproblemas:

3.3.1. ¿Es posible aún cuestionar el acuerdo de 1994 de la Junta de Administración? Consideran los magistrados que sí, por las siguientes razones desarrolladas en el punto VII, b) del fundamento 20:

i. es un acuerdo administrativo, por lo que no le resulta de aplicación el plazo legal para la revisión de los contratos;

ii. existen actos jurídicos, como las acciones de petición de herencia, cuya acción de revisión resulta imprescriptible, situación análoga al presente caso; y

iii. los miembros de la Junta de Administración están facultados para exigir el cumplimiento de la voluntad del testador, derecho que no está sujeto a un plazo legal.

3.3.2. ¿La presencia del representante del arzobispo validó el acuerdo de la Junta de Administración? Los magistrados consideran que no, por las siguientes razones desarrolladas en el punto VII, c) del fundamento 20:

i. el miembro designado por el arzobispado en la Junta de Administración es un representante legal o un mandatario; 
ii. el encargo de dicho representante en la Junta de Administración era administrar los bienes heredados por la universidad;

iii. no surten efectos legales los actos de los representantes que excedan el encargo asignado; $y$

ANÁLISIS ARGUMENTATIVO DE LA

iv. el representante del arzobispado en la Junta de Administración excedió sus funciones por lo que dicho acto no puede surtir efectos legales.

En suma, para los magistrados este acuerdo no es válido.

SENTENCIA DEL

TRIBUNAL CONS-

TITUCIONAL EN

EL CASO PUCP

3.4. ¿La administración a perpetuidad de forma compartida de los bienes de la PUCP afecta su derecho de propiedad? Los magistrados consideran que no se afecta el derecho de propiedad de la PUCP porque no es un derecho absoluto. El que así lo dijera el testador no es sino por la inercia de ciertas alocuciones mantenidas en el lenguaje de los juristas (punto VII, a) del fundamento 20).

3.5. iLa administración a perpetuidad de forma compartida de los bienes de la PUCP afecta la autonomía universitaria? Los magistrados consideran que la administración a perpetuidad de los bienes, de forma compartida con el representante de una institución ajena a la universidad, no afecta la autonomía universitaria por las siguientes razones desarrolladas en el punto VII, d, del fundamento 20:

i. la Ley Universitaria señala que la autonomía universitaria se ejerce de conformidad con la Constitución y las leyes;

ii. la autonomía universitaria no tiene carácter absoluto y puede haber injerencias mientras no sean «irrazonables y desproporcionadas», pues ello la desnaturalizaría; y

iii. las injerencias en la autonomía de la PUCP no son irrazonables ni desproporcionadas.

Sobre la base de la argumentación jurídica expuesta, los magistrados que suscriben la sentencia en mayoría concluyen y resuelven declarar INFUNDADO el recurso de agravio constitucional interpuesto por la PUCP.

\section{ANÁLISIS DE LA ARGUMENTACIÓN JURÍDICA DE LA SENTENCIA EN MAYORÍA}

Como intentaré demostrar, la argumentación jurídica del Tribunal Constitucional en la sentencia bajo análisis es deficiente, por lo que la decisión en mayoría resulta injustificada y arbitraria. Sin poder analizar el detalle de cada uno de los argumentos presentados, es posible resumir los principales problemas de la sentencia en los siguientes puntos: 
a. No justifica adecuadamente su decisión en el tema que motivó el recurso de agravio constitucional: la nulidad de la sentencia de la Corte Superior.

b. Se ocupa extensamente de un tema del que no debió ocuparse por no ser de su competencia y, al desarrollarlo, lo hace mal. Desatiende, en consecuencia, el objeto central del análisis de todo Tribunal Constitucional: el pedido de protección de los derechos constitucionales planteados por la demandante.

c. Emplea una serie de recursos retóricos como el énfasis innecesario o la ironía, que resulta inapropiado en un tribunal que pretende ser neutral e imparcial.

d. Los votos discrepantes revelan que no habría habido entre los magistrados una sincera actitud argumentativa.

Seguidamente, expondré las razones en las que justifico estas ideas:

\section{a. La sentencia no justifica su decisión sobre el tema para el que fue requerido}

Lo que la PUCP solicitó al Tribunal Constitucional mediante el recurso de agravio es que declare la nulidad de la resolución expedida por la Octava Sala Civil de la Corte Superior de Justicia de Lima y, en consecuencia, que declare la estimación de la demanda presentada por haberse obtenido los votos legalmente requeridos para tal efecto.

Sin aportar argumento alguno que justifique su decisión, el Tribunal Constitucional señala que:

[...] no existe vicio que acaree la nulidad, pues ésta [la sentencia de la Corte Superior] aparece suscrita por los señores magistrados que emitieron sus respectivas ponencias, no afectándose en modo alguno el sentido del fallo. Es más, se ha seguido cuidadosamente el procedimiento que con motivo de la desactivación de la Octava Sala Civil de la Corte Superior de Justicia de Lima dispuso la Resolución Administrativa $\mathrm{N}^{\circ}$ 292-2008-CE-PJSD (punto 6 del fundamento §1).

El párrafo transcrito nada justifica. Únicamente, se limita a constatar una situación que, a entender de los magistrados que suscriben la sentencia en mayoría, resulta regular sin dar mayores razones para dicha conclusión. No se pronuncia en absoluto sobre los argumentos de la demandada en los que fundamenta por qué considera que se habían obtenido los votos suficientes para considerar fundada la demanda. La mención de que una situación es regular no la convierte en regular; simplemente refleja una decisión injustificada al no haberse expresado las razones que la sustentan y revelan una actitud elusiva hacia el problema materia de la controversia en esta instancia. 
$\mathrm{Al}$ respecto, resulta relevante que los dos votos discrepantes que se incluyen en la sentencia desarrollen este punto al inicio de sus respectivas argumentaciones. Aunque no resultan favorables a la demanda de la universidad, resulta imprescindible pronunciarse sobre aquello que las partes someten a la decisión del tribunal. En este punto resulta pertinente citar el Código Iberoamericano de Ética Judicial que, en su artículo 25 , señala que «[...] la motivación debe extenderse a todas las alegaciones de las partes, o a las razones producidas por los jueces que hayan conocido antes del asunto, siempre que sean relevantes para la decisión».

\section{b. La sentencia se ocupa extensamente de una materia que no es de su competencia y, al hacerlo, lo hace mal}

Un segundo problema es que los magistrados que suscriben la decisión en mayoría se ocupan de una materia que no le correspondía: la interpretación de las disposiciones testamentarias. Además de no ser materia constitucional, se trata de un aspecto de la controversia que está siendo conocido por los jueces ordinarios. Al hacerlo, contraviene lo señalado en el artículo 139, inciso 2, de la Constitución, según el cual «ninguna autoridad puede avocarse a causas pendientes ante el órgano jurisdiccional ni interferir en el ejercicio de sus funciones $[\ldots]$...

Con ello no pretendo señalar que el Tribunal Constitucional no tenía nada que decir respecto a esta controversia. En la medida en que había derechos constitucionales amenazados, resultaba pertinente su pronunciamiento; sin embargo, resulta sorprendente que el único derecho constitucional del que se ocupa integralmente es un derecho que no fue invocado por la demandante.

En efecto, la PUCP solicitó la protección de su derecho a la propiedad, a la autonomía universitaria y a la inmutabilidad de los acuerdos; por el contrario, los magistrados que suscriben la sentencia en mayoría desarrollan toda su argumentación sobre la base del derecho a la herencia, que constituye el principal, si no el único, interés del demandado.

Incluso cuando no les correspondía pronunciarse sobre la interpretación de los testamentos de José de la Riva Agüero, el Tribunal Constitucional bien pudo dar algunas pautas generales sobre cómo pueden ser interpretados los testamentos en el marco de un Estado Constitucional. Lejos de ello, al interpretar las disposiciones testamentarias, los magistrados que suscriben la sentencia en mayoría no ponderan los distintos principios y valores constitucionales involucrados; para ellos, el contenido del derecho a la herencia es la medida a partir de la cual ha de entenderse el derecho de propiedad y la autonomía universitaria.

En efecto, empeñados en imponer una lectura formalista del testamento, los magistrados llegan a una interpretación desconcertante para un órgano al que se le confía la defensa de la Constitución y la protección de los derechos constitucionales. Sin considerarlo siquiera un asunto

ANÁLISIS ARGUMENTATIVO DE LA SENTENCIA DEL TRIBUNAL CONSTITUCIONAL EN EL CASO PUCP 
controvertible, el Tribunal Constitucional califica como «clarísima» la voluntad del testador de imponer a perpetuidad a la universidad una Junta de Administración de los bienes heredados.

De este modo, al haber más de una lectura posible según la literalidad de los testamentos, los magistrados optan por aquella que resulta más lesiva a los derechos constitucionales cuyo amparo fue solicitado por la PUCP. Considérese que las partes mantienen distintas interpretaciones de los testamentos de Riva Agüero - controversia que es de conocimiento de los tribunales ordinarios- - La PUCP propone una lectura conjunta de los testamentos de 1933 y 1938 que, respetando la literalidad de sus textos, sea deferente a los distintos principios y valores involucrados - como el respeto a la voluntad del causante, el principio de conservación de los testamentos, el derecho de propiedad o la autonomía universitaria-. Mientras tanto, el demandado asume una cierta interpretación literal del testamento de 1938, cuyo efecto sería lesivo a los principios ya mencionados.

Por ello, si algo debió hacer - y no hizo- el Tribunal Constitucional era señalar que la interpretación de los testamentos, como de cualquier acto jurídico público o privado, ha de ser armonizada con el marco constitucional establecido, de tal forma que ante una discrepancia sobre el significado de las disposiciones testamentarias ha de optarse por aquella que, respetando los criterios interpretativos de los testamentos, sea la que de mejor modo realice los principios y valores constitucionales que pudieran verse afectados. Por el contrario, estos magistrados hicieron $-\mathrm{y}$ no debieron hacer - una interpretación del significado de los testamentos de este caso en particular -inmiscuyéndose en asuntos de otros tribunales_ de la forma más lesiva posible a los derechos de la demandante, en concreto, al derecho a la propiedad y a la autonomía universitaria.

Es más: resulta elocuente —lo que será desarrollado más adelanteel énfasis que pone en ciertas expresiones, principalmente en las que pretenden justificar que no existe afectación a los derechos o intereses de la PUCP. Así, por ejemplo, cuando desarrolla lo referido a la autonomía universitaria, cita una sentencia anterior para recordar que esta institución se desnaturalizaría si se efectúan injerencias irrazonables y desproporcionadas. Sin embargo, añade: «[...] pero sólo eso: efectuar injerencias irrazonables y desproporcionadas, que evidentemente no es el caso, ni lejanamente. Muy por el contrario, en lo que debemos hacer énfasis es que, la autonomía universitaria se ejerce de conformidad con la Constitución y las leyes» (punto VII, d, del fundamento 20). Si la dependencia a un ente externo a perpetuidad para la administración de los bienes propios no es «ni lejanamente» una injerencia irrazonable y desproporcionada, es difícil imaginarse un supuesto que sí lo sería.

Sobre esta línea, se advierte que el afán de estos magistrados por desarrollar plenamente el derecho a la herencia, en desmedro de los 
derechos cuya protección solicita la universidad, los lleva a analizar temas que exceden de su competencia — como la interpretación de las disposiciones testamentarias-; cometen, en el camino, una serie de tropelías argumentativas cuya consecuencia es esta arbitraria decisión.

Así, por ejemplo, los magistrados toman como un presupuesto aquello que debe ser demostrado o justificado, pues es sobre lo que vienen discutiendo las partes. En efecto, en el considerando número 20, señalan como cuestión central lo siguiente: «el tema primordial de todo el contencioso que viene a este supremo intérprete, es determinar cuál de los testamentos debe prevalecer». Con esta frase, estos magistrados dan por asumido aquello que deberían justificar, es decir, que uno de los dos testamentos ha de prevalecer —que es la tesis del demandado—; o, en otros términos, asumen que no es posible una lectura conjunta y armónica de ambos testamentos — que es la tesis propuesta por la universidad-. Implícitamente, asumieron como propia y de forma injustificada la posición del demandado e incurrieron en la falacia de petición de principio.

Planteada así la dicotomía, atribuye a la universidad la postura de quien defiende la intangibilidad del testamento de 1993 frente al redactado en 1938. Puesta la universidad en tal situación, los magistrados la comparan como la de quien asume que una ley posterior no modifica una anterior, por lo que se permite calificar a la posición que a su entender asume la universidad como de un «absurdo jurídico». Literalmente señala:

El testamento de 1933 no puede prevalecer, bajo ningún pretexto, sobre uno posterior, como es el testamento de 1938. Pretender tal cometido sería abandonar el primer axioma de la técnica jurídica para una correcta interpretación de testamentos sucesivos: la prevalencia del testamento posterior por representar la última voluntad del testador (punto IX, 1 del fundamento 20).

Lo anterior revela, por decir lo menos, un actitud poco deferente hacia la PUCP, pues por el modo como presenta sus argumentos termina haciéndolos ver como razones insostenibles por el sentido común. Esta conducta se corresponde más con la que suele presentar una parte en un conflicto, pero no con la de un tercero imparcial. La PUCP no ha sostenido la intangibilidad del testamento de 1933 respecto al de 1938, sino que, en aplicación del principio de conservación de los testamentos, plantea una lectura conjunta de ambos documentos de forma tal que, respetando la voluntad del testador y la literalidad de los testamentos, se garanticen plenamente, además, los distintos bienes constitucionales involucrados, como el derecho de propiedad y la autonomía universitaria. Hacer ver que la universidad, contraria a toda racionalidad, se aferra únicamente al texto del testamento de 1933 es tergiversar sus argumentos para presentarla como una parte que no admite, siquiera, lo que por sentido común cualquier persona racional estaría dispuesta a admitir.

ANÁLISIS ARGUMENTATIVO DE LA SENTENCIA DEL TRIBUNAL CONSTITUCIONAL EN el caso pucp 
Además de la falacia señalada en el punto precedente, es posible advertir algunas otras. Como se sabe, las falacias son argumentos aparentemente sólidos pero que encubren una trampa lógica que, una vez detectada, las revelan como malos argumentos.

Así, en el punto IX, 3, c) del fundamento 20, señalan los magistrados: «[...] parece poco creíble que una universidad que alberga en su seno una planta de alta calidad de abogados y que es formadora de alumnos para prepararlos en esta importante profesión, durante tan largo período, no hubiere sido capaz de advertir cualquier incongruencia en los trabajos de la Junta Administradora». El efecto persuasivo de este argumento es evidente: apela al prestigio y a la autoridad de los abogados y docentes de la PUCP para justificar que el único modo de entender el testamento es reconociendo la perpetuidad en el mandato de la junta para administrar los bienes heredados por la PUCP. Pensar lo contrario sería desafiar el prestigio y autoridad de tales profesionales; por ello, no sería creíble.

Este argumento es falaz, pues, presentado de forma entimemática —es decir, con omisión de alguna de sus premisas-, asume hechos que no son necesariamente verdaderos. En efecto, para que la conclusión esté justificada —que el comportamiento de los docentes y abogados de la PUCP avale la perpetuidad de la labor administrativa de la junta-, requiere tener una serie de premisas no explicitadas, entre ellas, que tales docentes y abogados conozcan los testamentos y que conozcan de la existencia y detalle del trabajo que realizó la Junta de Administración. Es indudable que conocer tales situaciones no forma parte del trabajo del docente, puesto que su relación con la universidad no es la de un asesor jurídico sino, precisamente, la de un docente e investigador. Apelar, pues, al prestigio de los docentes y abogados formados en la PUCP para justificar la perpetuidad de las labores administrativas de la junta es una falacia.

En otro punto, la sentencia señala que «[...] si el temor o duda del testador llega hasta la propia existencia de la universidad, es lógico que también pueda haber albergado similares temores respecto a la eficiencia de su propia conducción. El que teme por lo más, teme con fundada razón por lo menos» (punto IX, 3, b) del fundamento 20).

Aquí los magistrados emplean un argumento analógico a fortiori; sin embargo, la corrección del razonamiento por analogía exige que exista una acreditada relación de semejanza entre los elementos a ser comparados —en este caso, entre «existencia» y «conducción eficiente»—. Lo primero está acreditado; lo segundo es asumido y no justificado, pues la única razón para fundamentar tal relación es que, a entender de los magistrados, resulta lógico pensarlo. Sería lógico pensar que si el testado tenía dudas sobre si la PUCP existiría al vigésimo año desde su muerte, también las tendría respecto del décimo año desde su muerte; sin 
embargo, plantearlo entre «existir» $\mathrm{y}$ «ser adecuadamente conducido» exige una justificación que los magistrados omiten. Por ello hacen de este argumento uno injustificado.

\section{c. El estilo de la sentencia}

Otro punto a ser destacado tiene que ver con la dimensión pragmática de la argumentación jurídica: es decir, todos aquellos elementos y recursos empleados en la argumentación con el objetivo de persuadir a otros, por ejemplo, mediante ciertas actitudes. Es una dimensión propia de las partes en un debate, por lo que resulta marginal en la decisión de un tribunal, salvo en lo que se refiere a los votos discrepantes. No obstante, en la decisión de la mayoría de los magistrados destacan ciertos recursos retóricos, como el énfasis o la ironía, por demás inadecuados en la decisión de un tribunal.

En efecto, en la sentencia en mayoría abunda el énfasis - mediante el subrayado y el resaltado de ciertas frases-, en contraste con el texto de los votos discrepantes que también emplean, aunque de forma moderada, este recurso. El énfasis resulta conveniente sobre todo para resaltar ideas centrales en textos extensos que permitan una mejor comprensión al lector de la sentencia; sin embargo, en este punto no me refiero a este uso del énfasis, sino al empleo de frases hechas de modo que, al ser formuladas, pretenden dar por concluida una discusión, aunque no por la solidez de la argumentación sino por lo altisonante de las frases empleadas. Su uso revela una suerte de hartazgo o de incomodidad ante la discusión. Equivale a alzar la voz durante un debate o discusión o a dar un golpe sobre la mesa. Ello podría ser explicable en las partes, pero resulta injustificable en el decisor. Revela imposición y parcialidad cuando es empleado por un decisor y niega la oposición de ideas.

Así, es más que elocuente que en dos oportunidades los magistrados terminen un argumento con la frase «y punto» (punto VII, c y IX, 3, $\mathrm{b}$, ambos del fundamento 20), que es del todo extraña a la redacción empleada por el Tribunal Constitucional durante todos los años en que funciona. En esta misma línea, se advierten frases del tipo «resultaría un despropósito» (IX, 3, a del fundamento 20) o «a todas luces resulta incongruente» (IX, 3, a del fundamento 20), entre otras.

En cuanto a la ironía, al igual que el énfasis, equivale a un recurso retórico que una parte emplea, durante un debate, para motivar la exasperación de la otra. Es igualmente explicable en las partes, pero injustificable por el decisor, quien, actuando desde la imparcialidad, no puede incluir expresiones que insinúen burla o menosprecio hacia los argumentos de alguna de las partes. Curiosamente, la ironía solo se emplea para hacer referencia a ciertos argumentos de la PUCP.

Así, por ejemplo, califica como «pretextos» las razones de la PUCP para no considerar vigente el mandato de la Junta de Administración (punto

ANÁLISIS ARGUMENTATIVO DE LA SENTENCIA DEL TRIBUNAL CONSTITUCIONAL EN el CAso PUCP 
IX, 1 del fundamento 20). En otro momento, con indudable sarcasmo, califica como «ingeniosos argumentos» la supuesta -e inviable - interpretación de la PUCP para preferir el testamento de 1933 ante el de 1938 (punto I, del fundamento 20).

Cuando se refiere a los temores, expresados en el testamento de 1933, del testador sobre la duración de la existencia de la universidad por sobre lo que infiere gratuitamente, como ya se vio, de que tales temores se extenderían al modo como se conduce la PUCP, señala con inocultable ironía — además de basarse en hechos falsos — lo siguiente:

[...] el hecho de que el Arzobispo deba enfrentar ahora acciones legales, que pretenden eliminar la participación de la Junta en la administración de los bienes heredados por la PUCP, en contra de la voluntad del causante, sólo nos lleva a pensar en cuán fundados y justificados fueron los temores de Riva Agüero (punto IX, 3, b del fundamento 20).

Precisamente en este último fundamento se advierte un extenso y desconcertante argumento completamente fuera de lugar en la sentencia. En él los magistrados se proyectan a un escenario dentro de cincuenta o sesenta años en el futuro y especulan sobre posibles nombres que entonces pudiera tener la PUCP. No hay modo de entender la pertinencia de este argumento como fundamento de la sentencia ni que pudiera originarse en un tribunal que pretende ser neutral, más aún cuando termina como un encendido alegato en favor de los intereses del demandando:

A este prominente peruano [José de la Riva Agüero y Osma] no le asaltó la idea de si la Universidad estaría en manos de Jesuitas, Dominicos o Franciscanos; si encausaban su fe en la línea Opus Dei, del Padre de Andrea, Sodalicio u otros. Él solo pensaba en la Jerarquía Católica, Apostólica y Romana, y punto. Hay que respetar, constitucionalmente, la voluntad del testador.

\section{d. ¿Qué revelan los votos discrepantes?}

Un punto final a ser analizado está referido a los dos votos extensos singulares que contiene la sentencia. Si bien en el Derecho es perfectamente admisible, y en ocasiones saludable, la discrepancia como resultado de una argumentación, sorprende que esta consista en posiciones abiertamente contrarias a todo lo indicado en los temas centrales por los magistrados que suscriben la sentencia en mayoría. La discrepancia excepcional y que versa sobre fundamentos últimos de ciertas instituciones jurídicas o del propio concepto del Derecho es consustancial a la labor de los órganos decisores colegiados. Sin embargo, la explícita contradicción de los temas centrales del recurso, más que una discrepancia, revelaría una actitud renuente a someterse al debate y fuerza de las razones. No es posible discrepar tanto y de forma tan profunda en puntos que se solicitan en el recurso de agravio constitucional; al hacerlo, solo 
se puede asumir que el debate no fue suficiente y que una de las partes asume una posición injustificada.

En efecto, opina el magistrado Beaumont que los recursos y la demanda de la PUCP debieron ser considerados improcedentes al no haberse acreditado la existencia de una amenaza real a los derechos fundamentales de la parte demandante. Por su parte, el magistrado Eto Cruz concluye que la demanda debió ser declarada fundada por considerar amenazados los derechos constitucionales invocados por la parte demandante.

De la sentencia en mayoría ya se ha comentado bastante; por ello, cabría destacar lo ponderados que resultan estos votos singulares en lo que se refiere a aspectos formales y sustanciales, respectivamente. Lejos de asumir posiciones parcializadas, estos magistrados, considerando los hechos y el Derecho, se ocupan de lo que debió ocuparse el Tribunal Constitucional, es decir, por una parte, analizar la procedencia formal del recurso (ise trata de un materia constitucional?, iexiste amenaza a los derechos de la PUCP?, idebe anularse la sentencia de la Corte Superior?) y, por otra, del fondo del asunto, es decir, la protección de los derechos constitucionales invocados (ilos testamentos pueden ser interpretados de tal forma que afecten gravemente un derecho constitucional?). El contraste de estos votos con el de la mayoría es evidente, pues las carencias de este último —que, precisamente, constituyen los puntos centrales de la discusión constitucional- se corresponden con las fortalezas de los primeros.

\section{CONCLUSIÓN}

Las sentencias de los altos tribunales, en particular de los tribunales constitucionales, exigen contar con una sólida justificación en atención a la trascendencia de sus decisiones. Así, tales decisiones no solo pueden esperar ser aceptadas por el carácter autoritativo del órgano que las expide, sino que deben aspirar a ser consideradas legítimas por la corrección y por la justificación de sus argumentos, que permitan hacerla ver como la mejor decisión posible a ser tomada en un determinado caso, tras considerar todos los elementos e intereses relevantes.

Solo así es posible concretar la función de pacificación y realizar la justicia por medio del Derecho. Lamentablemente, el análisis argumentativo realizado a esta sentencia suscrita en mayoría la revela como una decisión argumentativamente deficiente y, por tanto, injustificada.

ANÁLISIS ARGUMENTATIVO DE LA SENTENCIA DEL TRIBUNAL CONSTITUCIONAL EN EL CASO PUCP 